\title{
The Effectiveness of Letrozole-Electroacupuncture Adjuvant Therapy in Reducing Resistance and Pulsatility Indices in Women with Polycystic Ovarian Syndrome
}

\author{
Dhamayanti Eka Octavia, Uki Retno Budihastuti, Eriana Melinawati, \\ Nutria Widya Purna Anggraini, Eric Edwin Yuliantara, \\ Ida Nurwati, Cahyono Hadi
}

Department of Obstetrics and Gynecology, Faculty of Medicine, Universitas Sebelas Maret/ Dr. Moewardi Hospital, Surakarta

\section{ABSTRACT}

Background: Polycystic Ovarian Syndrome (PCOS) is a complex endocrine disorder and the cause of $40 \%$ of infertility cases. In recent years, letrozole as an aromatase inhibitor has been reported to be effective for ovulation induction. In addition, electro acupuncture therapy can reduce tonic activity in the sympathetic vasoconstrictor pathway to the uterus. This study aimed to determine the effectiveness of Letrozole-Electroacupuncture adjuvant therapy in reducing the Resistance Index and Pulsatility Indices in women with Polycystic Ovary Syndrome (PCOS).

Subjects and Method: This was an analytical observational study with a cohort approach. The subjects of the study were women aged 2045 years based on age, body mass index (BMI), and period of infertility aspects. The sample consisted of 30 people who were divided into 2 groups, namely group 1 with letrozole therapy, while group 2 with additional electroacupuncture therapy and then carried out pre- and post-intervention examinations on day 19 and 21. The dependent variables were the Resistance Index value and the Pulsaitility Index value. The independent variables were Letrozole and Electroacupuncture therapies. The Resistance and Pulsatility Indices were measured using USG transabdominal Color Doppler Voluson P6. The data were analyzed using the Mann Whitney test.

Results: The Pulsatility Index for group 1 on day 21 (Mean= 2.69; $\mathrm{SD}=0.87$ ) was higher than group $2(\mathrm{Mean}=1.97 ; \mathrm{SD}=0.57)$, and it was statistically significant $(\mathrm{p}=0.013)$.

Conclusion: Letrozole-EA therapy reduce the Resistance and Pulsatility Indices.

Keywords: Letrozole, acupuncture, endometrial receptivity, Polycystic Ovarian Syndrome

\section{Correspondence:}

Dhamayanti Eka Octavia. Department of Obstetrics and Gynecology, Faculty of Medicine, Universitas Sebelas Maret/ Dr. Moewardi Hospital, Surakarta 57126, Central Java. Email: dhamayantieka.de@gmail.com. Mobile: 081250355886.

\section{Cite this as:}

Octavia DE, Budihastuti UR, Melinawati E, Anggraini NWP, Yuliantara EE, Nurwati I, Hadi C (2020). The Effectiveness of Letrozole-Electroacupuncture Adjuvant Therapy in Reducing Resistance and Pulsatility Indices in Women with Polycystic Ovarian Syndrome. J Matern Child Health. 05(04): 422-429. https://doi.org/10.26911/thejmch.2020.05.04.09.

\section{Journal of Maternal and Child Health is licensed under a Creative Commons} Attribution-Non Commercial-Share Alike 4.o International License.

\section{BACKGROUND}

Polycystic Ovarian Syndrome (PCOS) is one of the most common complex and heterogeneous endocrine disorders in women with uncertain etiology and the cause of $40 \%$ of infertility cases (Waldman, 2019). PCOS is associated with decreased fertility and endometrial receptivity (Lopes, 2011). The metaanalysis study concluded that endometrial receptivity was a major inhibiting factor for pregnancy. 
Ultrasonography (USG) is one of the easiest ways to check endometrial receptivity for parameters such as endometrial thickness, endometrial pattern, endometrial volume, uterine artery Doppler studies, and endometrial blood flow. The impedance of blood flow in the endometrium is usually expressed as a Pulsatility Index (PI) and Resistance Index (RI) (Hung, 2007).

Letrozole is a third generation of an aromatase inhibitor. It is one of the treatment options for PCOS that does not cause a reduction in estrogen receptors in the endometrium. Letrozole could positively affect endometrial blood flow and improve endometrial receptivity (Zhong, 2019).

Several previous studies showed that decreased PI in the uterine arteries could occur after acupuncture therapy. The most likely causes were decreased tonic activity in the sympathetic vasoconstrictor pathway to the uterus and involvement of central mechanisms, with general inhibition of sympathetic outflow after acupuncture (Zhong, 2019).

Clinical studies showed the benefits of EA in treating infertility, including cases of PCOS. However, from various studies on EA, there were still many studies that did not have sufficient evidence to determine the effectiveness of acupuncture, especially in improving endometrial receptivity. An insufficient number of the sample, inaccurate methodology of the study, and insignificant results of the study were limitations of several studies. Based on these cases, the researcher was interested in conducting a study that aimed to determine the effect of electroacupuncture and letrozole in patients with PCOS to improve endometrial receptivity which could be assessed through the RI and PI results on examination using Doppler USG. The researchers expected that this study could add clinical evidence regarding alternative therapies and treatments for PCOS (Cheng, 2014).

\section{SUBJECTS AND METHOD}

\section{Study Design}

This was an analytical observational study with a cohort design. This study was conducted in Dr. Moewardi Hospital, Surakarta.

\section{Population and Sample}

The subjects of the study were women with PCOS aged 20-45 years who experienced infertility and selected by fixed disease sampling (the subjects were selected based on disease status, while exposure status varied regarding disease status that was "fixed"). The sample was divided into 2 groups. Group 1 consisted of 15 infertile women with PCOS as the subjects who had not received therapy and then given letrozole therapy. Group 2 consisted of 15 infertile women with PCOS who had not received therapy and then given letrozole-EA therapy. Before receiving therapy, the RI and PI values of each group on day 19 and 21 of the period were measured.

\section{Study Variables}

The dependent variables were the Resistance and the Pulsatility indices. The independent variables were Letrozole and Letrozole-EA.

\section{Operational Definition of Variables}

PCOS was enforced using the Rotterdam criteria. Patients were diagnosed with PCOS if she confirmed or positively had 2 or 3 Rotterdam criteria.

Acupuncture was carried out by inserting a needle into an accupoint that was specifically selected based on the meridian system at the point of CV 3 (Zhongji), CV 6 (Qihai), ST 29 (Guilai) bilateral, SP 6 (Sanyinjiao) bilateral, LI 4 (Hegu) bilateral, and ST 36 (Zusanli) bilateral. The needle was connected with an electrode stimulator (Hwato SDZ V, Shanghai China) for 15 minutes, continuous wave, frequency $2 \mathrm{~Hz}$. After 15 minutes, the stimulator turned off, the electrodes were cut, and the needle was removed. Electroacupuncture was carried out 2 times a week, up to 12 times. 
Letrozole was given at a dose of $2 \times 2.5 \mathrm{mg}$ per day on the second day of the period until the sixth day.

PI and RI Measurements were calculated automatically. The measurement was carried out on day 19 and 21 before and after therapy of the menstrual cycle. The measuring instrument: USG transadominal color Doppler of Voluson TM P6 brand.

\section{Data Analysis}

Mean difference after Letrozole vs. LetrozoleEA therapy were tested by independent t test.

\section{Research Ethics}

The research ethics consisted of consent, anonymity, confidentiality, and ethical clearance. Ethical clearance was issued by the Ethics Commission of Dr. Moewardi Hospital No. 237/II/HREC/2O2O.

\section{RESULTS}

In this study, the patients who became the study subjects aged around 26 to 44 years of age with an average age of 31 years. This was slightly different from a study in 2013 that $1.14 \%$ of women aged 15 to 19 years of age were diagnosed with PCOS using NIH criteria (Christensen et al., 2013).

In addition, the average value of BMI that was 25.4 to $25.7 \mathrm{~kg} / \mathrm{m} 2$ was classified as obese I. This is in line with the prevalence of obese women with PCOS that was $42 \%$ in Southeast Asia, 30\% in Spain, and 38\% in the Greek (Wiweko \& Mulya, 2008).

After therapy on day 19 and day 21, Letrozole-EA had a significant decrease compared to Letrozole on PI. In addition, after therapy, the PI had a significant decrease on day 21. There was no significant difference when letrozole was given before and after therapy from the mean value of RI and PI.

However, there was a significant difference when letrozole-electroacupuncture was given before and after therapy.

Table 1. The Characteristics of the Study Subjects

\begin{tabular}{lcccccc}
\hline \multicolumn{1}{c}{ Variable } & N & Mean & SD & Min. & Max. & p \\
\hline Age (year) & & & & & & \\
Letrozole +EA & 15 & 30.13 & 4.44 & 26 & 44 & 0.393 \\
Letrozole & 15 & 31.60 & 4.81 & 26 & 44 & \\
Weight (kg) & & & & & & \\
Letrozole +EA & 15 & 65.53 & 15.93 & 40 & 105 & 0.537 \\
Letrozole & 15 & 64.33 & 14.85 & 40 & 99 & \\
Height (cm) & & & & & & \\
Letrozole +EA & 15 & 156.80 & 3.63 & 150 & 163 & 0.888 \\
Letrozole & 15 & 157.73 & 4.50 & 150 & 167 & \\
BMI( kgBW/m2) & & & & & & \\
Letrozole & 15 & 25.40 & 5.24 & 17 & 39 & 0.760 \\
Letrozole+EA & 15 & 25.70 & 5.08 & 17 & 36 & \\
Duration of infertility (year) & & & & & & \\
Letrozole & 15 & 4.73 & 2.28 & 1 & 8 & 0.784 \\
Letrozole+EA & 15 & 5 & 2.95 & 2 & 10 & \\
\hline
\end{tabular}


Octavia et al./ Letrozole-Electroacupuncture Adjuvant Therapy on Resistance and Pulsatility Indices

Table 2. The mean value of the Resistance Index and Pulsatility Index Pre- and Postintervention

\begin{tabular}{|c|c|c|c|c|c|c|c|c|}
\hline \multirow[t]{2}{*}{ Outcome } & \multirow[t]{2}{*}{$\mathbf{N}$} & \multicolumn{2}{|c|}{$\begin{array}{c}\text { Pre- } \\
\text { Intervention }\end{array}$} & \multicolumn{2}{|c|}{$\begin{array}{c}\text { Post- } \\
\text { Intervention }\end{array}$} & \multicolumn{2}{|c|}{$\begin{array}{c}\text { Post-Pre } \\
\text { Difference }\end{array}$} & \multirow[t]{2}{*}{ p } \\
\hline & & Mean & SD & Mean & SD & Mean & SD & \\
\hline \multicolumn{9}{|l|}{ RI Day 19} \\
\hline Letrozole+EA & 15 & 0.93 & 0.07 & 0.87 & 0.07 & 0.06 & 0.09 & 0.367 \\
\hline Letrozole & 15 & 0.94 & 0.06 & 0.90 & 0.08 & 0.03 & 0.08 & \\
\hline \multicolumn{9}{|l|}{ RI Day 21} \\
\hline Letrozole+EA & 15 & 0.94 & 0.07 & 0.78 & 0.01 & 0.16 & 0.12 & 0.007 \\
\hline $\begin{array}{l}\text { Letrozole } \\
\text { PI Day } 19\end{array}$ & \multicolumn{7}{|c|}{ PI Day 19} & \\
\hline Letrozole+EA & 15 & 3.86 & 0.56 & 2.22 & 0.64 & 1.63 & 1.24 & 0.009 \\
\hline Letrozole & 15 & 3.62 & 1.04 & 2.99 & 0.89 & 0.63 & 0.61 & \\
\hline \multicolumn{9}{|l|}{ PI Day 21} \\
\hline Letrozole+EA & 15 & $3 \cdot 50$ & 0.37 & 1.97 & 0.86 & 1.53 & 1.11 & 0.023 \\
\hline Letrozole & 15 & 3.51 & 1.27 & 2.68 & 0.87 & 0.83 & 0.87 & \\
\hline
\end{tabular}

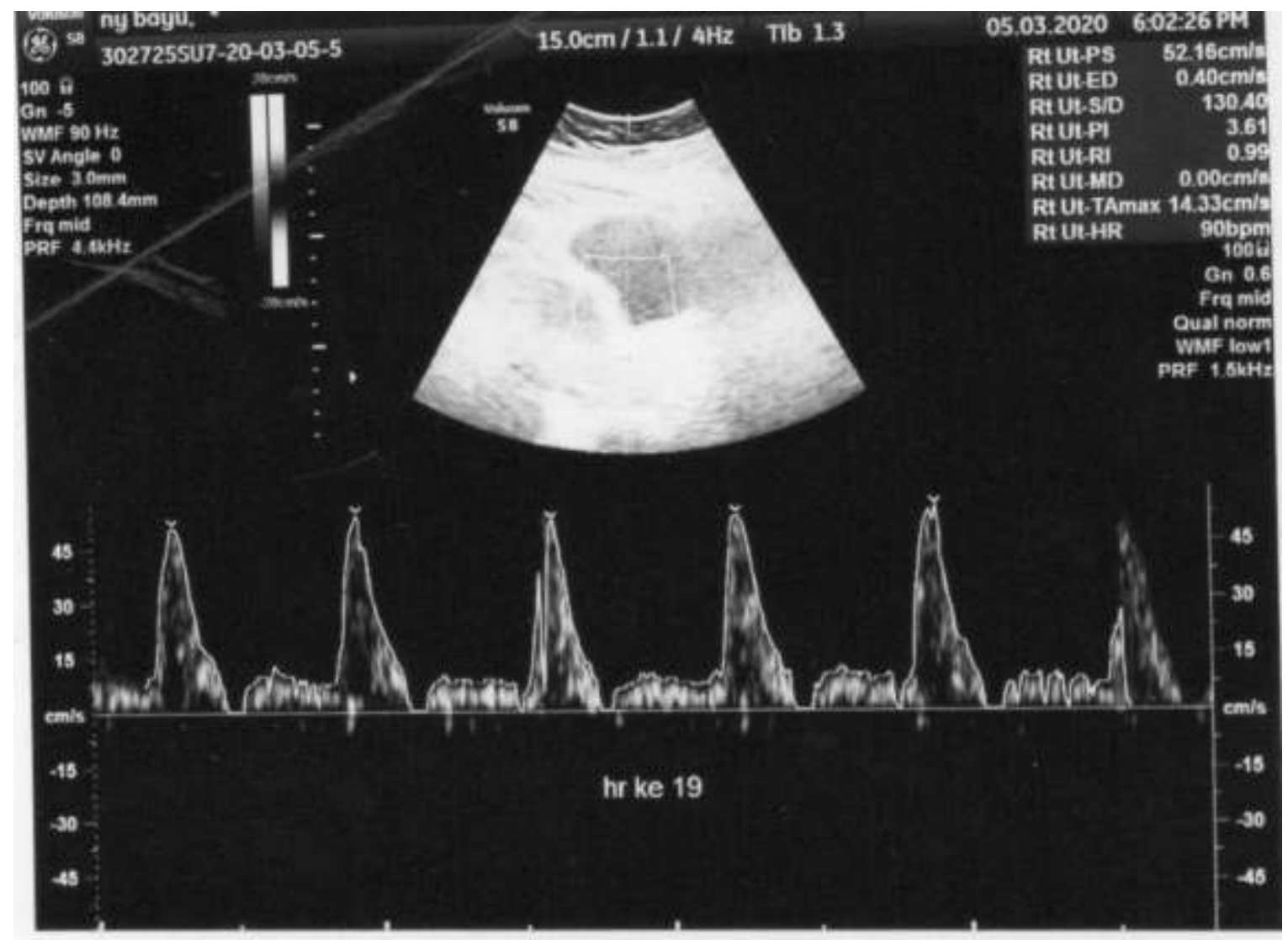

Figure 2. The figure of Color Doppler in women with PCOS before EA-letrozole treatment (author documentation). PI value of 3.61 and an RI value of 0.99 indicate that $P I>3$ was at risk of implantation failure due to poor endometrial receptivity 


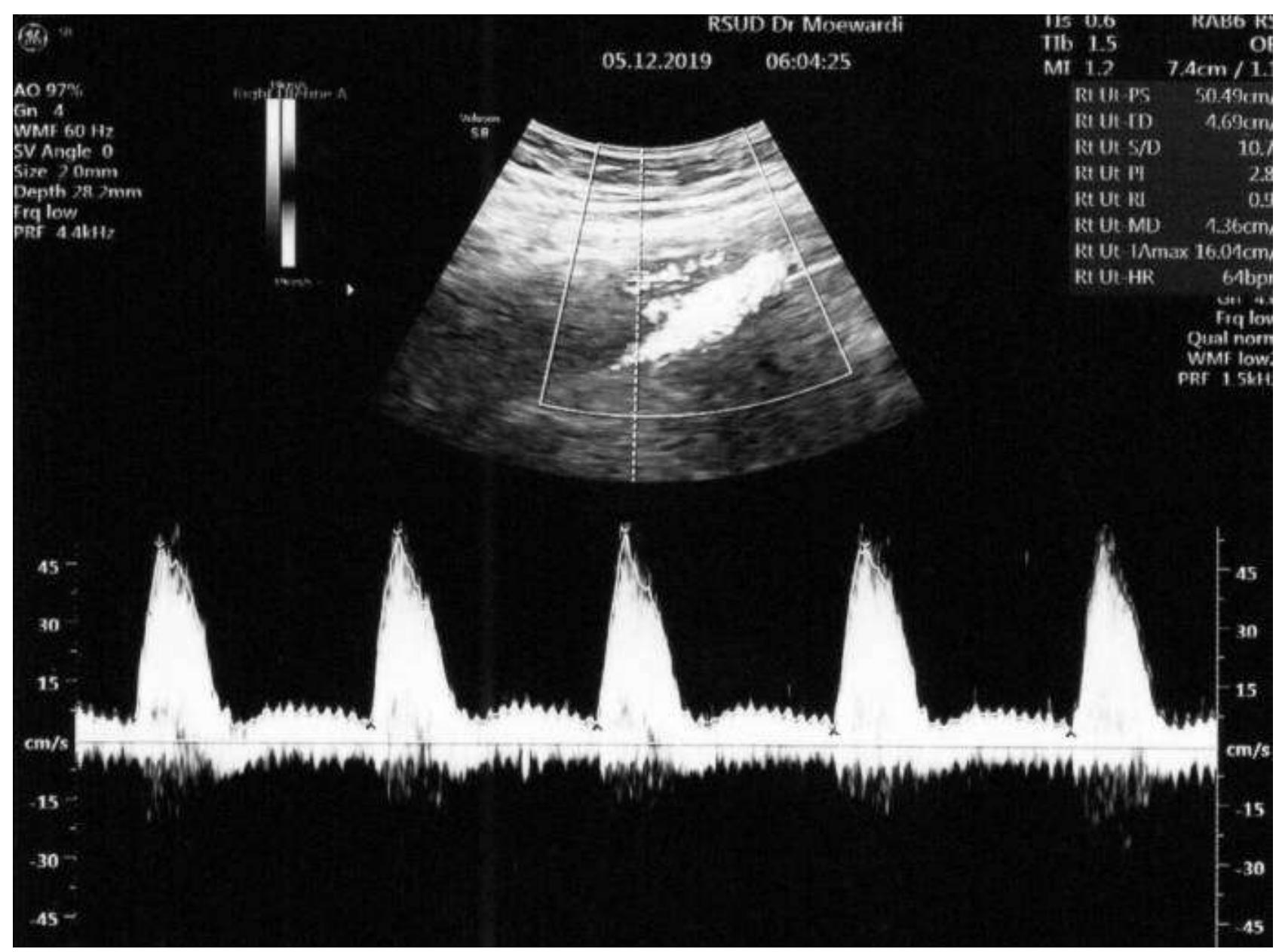

\section{Figure 3. The figure of Color Doppler in women with PCOS after EA-letrozole treatment (author documentation)}

\section{DISCUSSION}

The excessive response to gonadotropin stimulation, increased resistance of blood vessels to uterine blood flow, and reduced endometrial receptivity were the mechanisms for the occurrence of PCOS (Ozkan, 2007). Increased endometrial and sub-endometrial blood flow was good for implantation and pregnancy.

The absence of endometrial and subendometrial blood flow was always accompanied by old age, a thin endometrium, and high PI and/or RI values. This was a poor uterine environment. Therefore, the endometrial and subendometrial blood flow could more accurately reflect the endometrial receptivity which could be assessed by PI and RI (Gao, 2007).
Post-therapy changes were the effect of the mechanism of action of letrozole which prevented the hypothalamic-pituitary axis from negative estrogenic feedback, thus increasing gonadotropin secretion and producing stimulation of ovarian follicles. In addition, it has a local effect on the ovaries and the accumulation of androgens increased the sensitivity of the follicles to FSH.

Letrozole was a very strong and selective competitive non-steroidal aromatase inhibitor. Letrozole had a half-life of about 45 hours. The mechanism of stimulation of the ovaries by letrozole was a central effect on the prevention of the hypothalamic-pituitary axis from negative estrogen feedback. The local ovarian effect blocked the conversion of an- 
drogens to estrogen. With the concomitant accumulation of androgens in the ovaries, it enhanced the expression of FSH receptors follicles and promoted folliculogenesis. (Elkattan, 2013).

The positive effect of letrozole-electroacupuncture therapy was supported by previous studies that a decrease in PI in the uterine arteries could occur after the electroacupuncture therapy. The most likely causes were decreased tonic activity in the sympathetic vasoconstrictor pathway to the uterus and the involvement of central mechanisms, with general inhibition of sympathetic outflow after acupuncture (Zhong, 2019).

Adjuvant EA therapy could increase ovulation in patients with PCOS by affecting beta-endorphin secretion in the central nervous system and inhibition of sympathetic tonus. Electroacupuncture also increased uterine blood flow and reduced uterine vasoconstriction by the sympathetic nervous system, thus increasing endometrial receptivity (Farajzadeh et al., 2017).

The role of $\beta$-endorphin was important for women with PCOS who had therapy because anovulation in PCOS showed high plasma $\beta$-endorphins, as well as an increase in sympathetic nerve activity which manifested as low skin temperature. These problems could be treated with EA. Electroacupuncture would inhibit the vasomotor center and decrease sympathetic tonus and blood pressure. This is the key to why EA could help managing patients with PCOS (Stener-Victorin et al., 2010).

Electroacupuncture was effective in PCOS both psychologically and physiologically. The low frequency of EA stimulated muscle mechanoreceptors and the surrounding tissue. Electroacupuncture could also release beta-endorphins through two mechanisms. The first mechanism was by the hypothalamus and by inhibiting the sympathetic nervous system. The second mechanism was the beta-endorphin and adrenocorticotropic (ACTH) hormones in the blood. These two systems could reduce the sympathetic effect, thus increasing endometrial blood flow in women with PCOS (Jedel et al., 2011).

Acupuncture therapy had a variety of effects depending on the stimulation (amount of manual manipulation or frequency of electrical stimulation on the EA), the number of acupuncture needles inserted, and the duration of therapy given. Therefore, many variables could affect the results of acupuncture studies (Stener-Victorin et al., 2010). Besides letrozole and EA, lifestyle therapy was the first step in the management of PCOS, especially if it was associated with overweight. Pharmacotherapy was used to treat clinical manifestations such as irregular menstruation, hirsutism, and fertility problems in women (Bellver et al., 2018).

\section{AUTHOR CONTRIBUTION}

Dhamayanti Eka Octavia, Uki Retno Budihastuti, Eriana Melinawati, Nutria Widya Purna Anggraini, Eric Edwin Yuliantara, Ida Nurwati, and Cahyono Hadi did electroacupuncture therapy, measured the resistance and pulsatility indices, did data analysis, and wrote the manuscript.

\section{CONFLICT OF INTEREST}

The authors declare there is no conflict of interest.

\section{FUNDING AND SPONSORSHIP}

This study used personal costs and funds.

ACKNOWLEDGEIMENT

We would like to thank the director of Dr. Moewardi Hospital who has allowed to conduct this study.

\section{REFERENCE}

Budihastuti UR, Melinawati E, Sulstyowati S, Nurwati I (2019). Electroacupuncture Effect on Polycystic Ovary Syndrome to Improve Oocytes' Growth. Med Acu- 
Octavia et al./ Letrozole-Electroacupuncture Adjuvant Therapy on Resistance and Pulsatility Indices

punct. 31(6): 1-5. https://dx.doi.org/10.1089\%2Facu.2019.1354.

Cheng KJ (2014). Neurobiological mechanisms of acupuncture for some common illnesses: A Clinician's Perspective. J Acupunct Meridian Stud. 7(3): 105114. https://doi.org/10.1016/j.jams.2013.07.008.

Christensen SB, Black MH, Smith N, Martinez MM, Jacobsen SJ, Porter AH, et al. (2013). Prevalence of polycystic ovary syndrome in adolescents. Fertil Steril. 100(2): 470-7. https://doi.org/10.1016/j.fertnstert.2013.04.001.

Chuderland D, Ben-Ami I, Kaplan-Kraicer R, Grossman H, Ron-El R, Shalgi R (2013). The role of pigment epitheliumderived factor in the pathophysiology and treatment of ovarian hyperstimulation syndrome in mice. J Clin Endocrinol Metab. 98(2): E258-E266. https://doi.org/10.1210/jc.2012-3037.

Elkattan EA (2013). Ultrasonographic markers of endometrial receptivity of letrozole and clomiphene citrate in unexplained infertile women. Middle East Fertility Society, 18(2): 84-88. https://doi.org/10.1016/j.mefs.2012.07.008 Farajzadeh F, Ghaderi F, Bastani P (2017). Treatment of polycystic ovarian syndrome using electroacupuncture: A case report. Int J Women's Health Reprod Sci. 5(1): 76-79. http://dx.doi.org/10.15296/ijwhr.2017.14.

Gao M, Zhao X, Li W, Liu G, Jia X (2007). Assessment of uterine receptivity by endometrial and subendometrial blood flows measured by vaginal color doppler ultrasound in women undergoing IVF treatment. J Reprod Contracept Obstet Gynecol: 18(3): 205-212. https://doi.org/10.1016/S1001-7844(07)60025-X.

Hung E, Ng Y, Chi C, Chan W, Tang OS, Shu $\mathrm{W}$ (2007). The role of endometrial blood flow measured by three-dimensional power Doppler ultrasound in the prediction of pregnancy during in vitro fertilization treatment. Eur J Obstet Gynecol Reprod Biol. 135(1): 8-16. https://doi.org/10.1016/j.ejogrb.2007. o6.006.

Kim A, Jung H, Choi WJ, et al. (2014). Detection of endometrial and subendometrial vasculature on the day of embryo transfer and prediction of pregnancy during fresh in vitro fertilization cycles. Taiwan J Obstet Gynecol, 53(3): 360365. https://doi.org/10.1016/j.tjog.2013.05.007.

Kusuma AC, Oktari N, Mihardja H, Srilestari A, Simadibrata CL, Hestiantoro A, Wiweko B, Muna N (2019). Electroacupuncture enhances number of mature oocytes and fertility rates for in vitro fertilization. Med Acupunct. 31(5): 289297. https://doi.org/10.1089/acu.2019.1368 .

Lim CED, Ng RWC, Xu K (2016). Acupuncture for Sindrom Ovarium Polikistik. Cochrane Database Syst Rev. (5): CDoo7689.

Lopes Imrs, Maria CPB, Manuel DJB, Ricardo SS, Edmund CB, Jose SMJ (2011). Endometrium in women with polycystic ovary syndrome during the window of implantation. Rev Assoc Med Bras. 57(6): 702-209. https://doi.org/10.1590/s0104-42302011000600020.

Ozkan S, Vural B, Calıskan E, Bodur H, Erkan Turkoz, Vural F (2007). Color doppler sonographic analysis of uterine and ovarian artery blood flow in women with polycystic ovary syndrome. J Clin Ultrasound. 35(6): 305-13. https://doi.org/10.1002/jcu.20358.

Palihawadana TS, Wijesinghe PS, Seneviratne HR (2015). A comparison of endometrial thickness following aug- 
menttation of ovulation with clomifene citrate or letrozole in women with ovulatory infertility. Ceylon Med J. 6o(2): 48-52. https://doi.org/10.4038/cmj.v6oi2.8152.

Stener-Victorin E, Wu X (2010). Effects and mechanisms of acupuncture in the reproductive system. Auton Neurosci Basic lin. 157(1-2): 46-51. https://doi.org/10.1016/j.autneu.2010.03.006.

Waldman IN, Legro RS (2019). Polycystic Ovary Syndrome. The Ovary. 415-453. https://doi.org/10.1016/B978-0-12-813209-8.00026-1.

Wang L, Wen X, Shulan L, Zhao J, Yang T, Yang X (2019). Comparison of endometrial receptivity of clomiphene citra- te versus letrozole in women with polycystic ovary syndrome: a randomized controlled study. Gynecol Endocrinol. 35(10):862-865. https://doi.org/10.108o/09513590.2019.1612358.

Wiweko B, Mulya R. (2008). Profil resistensi insulin pada pasien sindrom ovarium polikistik (SOPK) di RS Dr. Cipto Mangunkusumo Jakarta. J Obstetri Ginekologi Indonesia. 32(2): 93-8.

Zhong Y, Zeng F, Liu W, Ma J, Guan Y, Song $Y$ (2019). Acupuncture in improving endometrial receptivity: A systematic review and meta- analysis. BMC Complementary and Alternative Medicine. 19(1): 1-19. https://doi.org/10.1186/s12906-019-2472-1. 